\title{
How long is a piece of string? less than half your height. five steps from science to screening: a mini review
}

\begin{abstract}
Central obesity is harmful in terms of cardiometabolic risk, but it can only be measured accurately with expensive equipment. The aim of this review is to summarise how the scientific evidence has accumulated to the extent that waist-to-height ratio (WHtR), which has been shown to be a simple proxy for central obesity, is starting to be adopted into public health policy and can now be used as a simple, early screening tool. A boundary value of WHtR 0.5 has been suggested as the first level of risk. This translates into the simple message "Keep your waist to less than half your height". However, to check if WHtR is less than 0.5 does not even need a tape measure. A piece of string will suffice. The string is used to measure the person's height and then it is folded in half to see whether it fits easily around the person's waist. If it does not, early health risk is indicated and further screening is indicated. Thus the string acts as a simple, cheap, signposting tool for early health risk. At long last we have the answer to that age old question: "How long is piece of string?" The answer is "Less than half a person's height if we want to improve public health through opportunistic screening."
\end{abstract}

Volume 7 Issue 2 - 2017

\author{
Margaret Ashwell \\ Cass Business School, City, University of London, UK
}

Correspondence: Margaret Ashwell OBE, FAfN, RNutr(Public Health), Ashwell Associates, Ashwell Street, Ashwell, Hertfordshire, SG7 5PZ; United Kingdom,

Email margaret@ashwell.uk.com

Received: June 07, 2017| Published: August 01, 2017
Abbreviations: BMI, body mass index; WHtR, waist-to-height ratio; VAT, visceral adipose tissue

\section{Introduction}

This short review aims to summarise, in five simple steps, how a body of science has accumulated which is starting to be adopted into policy and which can now be translated into very simple early screening tool for cardiometabolic risk factors. The Figure summarises these five steps (Figure 1).

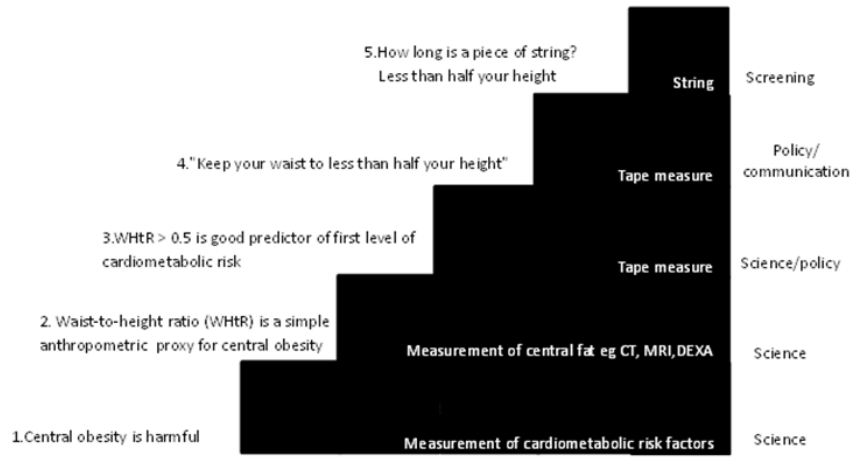

Figure I 5 Steps from science to screening.

\section{Step I: Central obesity is harmful}

First proposed by Vague more than 50years ago, ${ }^{1}$ it is now generally acknowledged that central fat depots are more harmful than subcutaneous fat depots in terms of morbidity and mortality. ${ }^{2,3}$
This is not only because they release their free fatty acids directly into the portal circulation ${ }^{4}$ but also because they produce more inflammatory factors than subcutaneous fat depots. These factors, such as TNF alpha, cause generation of reactive oxygen species (ROS) in the mitochondria leading to mitochondrial loss and dysfunction (decreased mitochondrial biogenesis). This, in turn, causes more ROS to be generated in a vicious cycle. It may be that the mitochondrial dysfunction, which inhibits glucose-stimulated insulin secretion to impair $\beta$-cell function in the pancreas, decreases glucose utilization in the muscles, and increases gluconeogenesis in the liver. All these effects can lead to increased insulin resistance and diabetes and also to increased cardiometabolic risk. ${ }^{5}$ Even normal weight people with central obesity show increased morbidity in relation to cardiometabolic risk than compared with normal weight people without central obesity. ${ }^{6-8}$ Further, their mortality is also increased..$^{9-13}$ In UK, approximately $25 \%$ of normal weight adults (just under $10 \%$ of all adults) would be classified as having normal weight central obesity i.e. Body Mass Index (BMI) between 18.5 and 25 and waistto-height ratio (WHtR) above $0.5 .^{14}$

\section{Step 2:Waist-to-height ratio is a simple anthropometric proxy for central obesity}

Central obesity has several simple anthropometric proxies: waist circumference, waist-to-hip ratio and waist-to-height ratio (WHtR) are the commonest. More complex indices include Conicity index, ${ }^{15}$ the Lipid accumulation product, ${ }^{16}$ the visceral adipose index, ${ }^{17}$ A Body Shape Index ${ }^{18}$ and a Body Roundness Index..$^{19}$ Comparisons of several of these anthropometric indices have found that WHtR was the best anthropometric proxy for visceral adipose tissue (VAT) mass when measured by Computed Tomography ${ }^{20}$ or by DEXA scanning. ${ }^{21}$ 


\section{Step 3: Waist-to-height ratio more than 0.5 is a good predictor of first level cardiometabolic risk}

The ratio $(\mathrm{R})$ of the waist circumference $(\mathrm{W})$-to-height $(\mathrm{Ht})$ (WHtR) was originally proposed more or less simultaneously in $\operatorname{Japan}^{22}$ and the $\mathrm{UK}^{23}$ as a way of assessing shape and monitoring risk reduction. Both proposers suggested that $\mathrm{WHtR}$ values above 0.5 should indicate increased health risk. WHtR had, in fact, been used a few years before rather apologetically because hip circumferences were not available to calculate the, then popular, waist to hip ratio. ${ }^{24}$

Many studies have now supported using WHtR 0.5 for first level risk in adults and a pooled analysis of suggested cut-off values produced a weighted mean boundary value of $0.5 .^{25}$ The first systematic review to show that WHtR performed better than BMI in predicting cardiometabolic risk was published in $2008 .{ }^{26}$ Since then, other systematic reviews and meta-analyses have compared several anthropometric indices including WHtR with BMI and always found that WHtR was the best predictor of cardiometabolic risk in adults ${ }^{27-29}$ and in children. ${ }^{30}$

More recently the boundary value of WHtR 0.5 has been used to highlight the problem of normal weight central obesity. People with normal weight central obesity show increased morbidity in relation to cardiometabolic risk greater than those in normal weight people without central obesity e.g. ${ }^{6-8}$ Further, their mortality is also increased e.g. ${ }^{9-13}$ Using data from the last 2 years of the UK National Diet and Nutrition Survey (NDNS 2013-2014) (n=1108 adults aged 19 and over), respondents were cross-classified on the anthropometric indices BMI and waist-to-height ratio (WHtR). Approximately 25\% of normal weight adults (just under $10 \%$ of all adults) would be classed as having normal weight central obesity i.e. BMI 18.5 and below 25 and WHtR above 0.5. ${ }^{14}$ If we want to avoid 'missing' the normal weight central obese population, waist-to-height ratio values should be used to categorise populations.

\section{Step 4: "Keep your waist to less than half your height" is a simple public health policy message}

This simple public health message arising from the adoption of a boundary value of 0.5 was first suggested in relation to children and adolescents. ${ }^{31}$ Although many studies have discovered more precise cut-off values for WHtR in their particular populations, several have suggested that the simple value of 0.5 is perfectly adequate for this public health policy message: "Keep your waist to less than half your height". ${ }^{32-34}$ Not only has WHtR been promoted as a primary screening tool in its own right ${ }^{35}$ but it has been used as the anthropometric proxy within more complex opportunistic screening tools such as DIABSCORE. ${ }^{36}$ In 2015, the New Zealand (NZ) Ministry of Health was the first Government department to publish weight management guidance including WHtR as one available measure. By applying WHtR to NZ National Adult Health Survey data, WHtR $>0.5$ classified more people, particularly men, as being at 'early increased risk' compared with waist circumference and BMI. ${ }^{37}$ One of the barriers for adopting a new measure into public health policy is that policy makers do not like the size of the 'at risk' population to significantly increase or decrease. If this happens, they can be accused of manipulating the data to suit their policy needs.

Using the NDNS adult sample described in Step 3, we found that WHtR $>0.5$ would put $63 \%$ at first level risk and WHtR $>0.6$ would put $22 \%$ of the adult population 'at risk'. This compares with $59 \%$ who are above BMI 25 and $23 \%$ who are above BMI 30 . Thus, the size of the 'at risk' population would not vary greatly -but the normal weight central obesity population would not be 'missed' and those targeted would be more likely to have abnormal cardiometabolic risk factors. ${ }^{7}$

\section{Step 5: how long is a piece of string? less than half your height for simple screening}

For obesity, diabetes and heart disease (in developed and developing countries), prevention should start in childhood and any early, opportunistic screening method should be simple and cheap. Ideally it should involve measurements which can be done reliably by parents and carers. ${ }^{38}$ Measuring WHtR does not require weighing scales but would normally require a tape measure for height and waist circumference. However, to check if WHtR is more than 0.5 does not even need a tape measure. A piece of string will suffice. The string is used to measure the child's height and then it is folded in half to see whether it fits easily around the child's waist. If it does not, early health risk is indicated and further screening is indicated. Parents or carers can do the string test or they can watch the child to do it themselves. If the string does not fit, then how big is the gap? Maybe two fingers, maybe three? Whatever the gap, parents can work with their child to see if the gap can be made smaller for the next string test. This method has already been adopted as Government policy in Thailand. ${ }^{8,39}$ In UK it has been used in Community ${ }^{40}$ and Charity ${ }^{41}$ projects. Thus the string acts as a simple, cheap, signposting tool for early health risk and, at long last, we have the answer to that age old question: How long is piece of string? The answer is less than half a person's height if we want to improve public health.

\section{Conclusion}

There is now very good evidence to support the potential use for waist-to-height ratio as an indicator of early health risk at all levels. The messages based on science in Steps 1, 2 and 3 can be translated into a policy/ communication message in Step 4 which can then be translated into a very simple screening tool in Step 5. The laboratory equipment needed at the science stages is replaced by a simple piece of string for community screening.

\section{Acknowledgements}

None.

\section{Conflict of interest}

The author declares no conflict of interest.

\section{References}

1. Vague J. The degree of masculine differentiation of obesities: a factor determining predisposition to diabetes, atherosclerosis, gout, and uric calculous disease. Am J Clin Nutr. 1956;4(1):20-34.

2. Zhang M, Hu T, Zhang S, et al. Associations of Different Adipose Tissue Depots with Insulin Resistance: A Systematic Review and Meta-analysis of Observational Studies. Sci Rep. 2015;5:18495.

3. Lee SW, Son JY, Kim JM, et al. Body fat distribution is more predictive of all-cause mortality than overall adiposity. Diabetes Obes Metab. 2017; 10:13050.

4. Bjorntorp P. Obesity and adipose tissue distribution as risk factors for the development of disease. A review. Infusions therapie. 1990;17(1):24-27.

5. Liu J, Shen W, Zhao B, et al. Targeting mitochondrial biogenesis for preventing and treating insulin resistance in diabetes and obesity: Hope from natural mitochondrial nutrients. Adv Drug Deliv Rev. 2009;61(14):13431352. 
6. Srinivasan SR, Wang R, Chen W, et al. Utility of waist-to-height ratio in detecting central obesity and related adverse cardiovascular risk profile among normal weight younger adults (from the Bogalusa Heart Study). Am J Cardiol. 2009;104(5):721-724.

7. Ashwell M, Gibson S. Waist-to-height ratio as an indicator of 'early health risk': simpler and more predictive than using a 'matrix' based on BMI and waist circumference. BMJ Open. 2016;6(3):e010159.

8. Thaikruea L, Thammasarot J. Prevalence of normal weight central obesity among Thai healthcare providers and their association with CVD risk:a cross-sectional study. Sci Rep. 2016;6:37100.

9. Coutinho T, Goel K, Correa de Sa D, et al. Combining body mass index with measures of central obesity in the assessment of mortality in subjects with coronary disease: role of normal weight central obesity. J Am Coll Cardiol. 2013;61(5):553-560.

10. Ashwell M, Mayhew L, Richardson J, et al. Waist-to-height ratio is more predictive of years of life lost than body mass index. PLOS One. 2014;9(9):e103483.

11. Sahakyan KR, Somers VK, Rodriguez-Escudero JP, et al. Normal-Weight Central Obesity: Implications for Total and Cardiovascular Mortality. Ann Intern Med. 2015;163(11):827-835.

12. Sharma S, Batsis JA, Coutinho T, et al. Normal-Weight Central Obesity and Mortality Risk in Older Adults With Coronary Artery Disease. Mayo Clin Proc. 2016;91(3):343-351.

13. Hamer M, O’Donovan G, Stensel D, et al. Normal-Weight Central Obesity and Risk for Mortality. Ann Intern Med. 2017;166(12):917-918.

14. Ashwell M, Gibson S. Normal weight central obesity: the value of waist-to-height ratio in its identification. Waist measurement, not BMI, is stronger predictor of death risk, study finds. BMJ. 2017;357:j2033.

15. Valdez R, Seidell JC, Ahn YI, et al. A new index of abdominal adiposity as an indicator of risk for cardiovascular disease. A cross-population study. Int J Obes Relat Metab Disord. 1993;17(2):77-82.

16. Kahn HS. The "lipid accumulation product" performs better than the body mass index for recognizing cardiovascular risk: a population-based comparison. BMC Cardiovasc Disord. 2005;5:26

17. Amato MC, Giordano C, Galia M, et al. Visceral Adiposity Index: a reliable indicator of visceral fat function associated with cardiometabolic risk. Diabetes Care. 2010;33(4):920-922.

18. Krakauer NY, Krakauer JC. A new body shape index predicts mortality hazard independently of body mass index. PLoS One. 2012;7(7):e39504.

19. Thomas DM, Bredlau C, Bosy-Westphal A, et al. Relationships between body roundness with body fat and visceral adipose tissue emerging from a new geometrical model. Obesity (Silver Spring). 2013;21(11):2264 2271.

20. Roriz AK, Passos LC, de Oliveira CC, et al. Evaluation of the accuracy of anthropometric clinical indicators of visceral fat in adults and elderly. PLoS One. 2014;9(7):e103499.

21. Swainson MG, Batterham AM, Tsakirides C, et al. Prediction of wholebody fat percentage and visceral adipose tissue mass from five anthropometric variables. PLoS One. 2017;12(5):e0177175.

22. Hsieh SD, Yoshinaga H. Waist/height ratio as a simple and useful predictor of coronary heart disease risk factors in women. Intern Med. 1995;34(12):1147-1152.

23. Ashwell M, LeJeune S, McPherson K. Ratio of waist circumference to height may be a better indicator of need for weight management. $B M J$ 1996;312(7027):377.
24. Higgins M, Kannel W, Garrison R, et al. Hazards of obesity-the Framingham experience. Acta Med Scand Suppl. 1988;723:23-36.

25. Browning LM, Hsieh SD, Ashwell M. A systematic review of waistto-height ratio as a screening tool for the prediction of cardiovascular disease and diabetes: 0.5 could be a suitable global boundary value. Nutr Res Rev. 2010;23(2):247-269.

26. Lee CM, Huxley RR, Wildman RP, et al. Indices of abdominal obesity are better discriminators of cardiovascular risk factors than BMI: a metaanalysis. J Clin Epidemiol. 2008;61(7):646-653.

27. Ashwell M, Gunn P, Gibson S. Waist-to-height ratio is a better screening tool than waist circumference and BMI for adult cardiometabolic risk factors: systematic review and meta-analysis. Obes Rev. 2012;13(3):275-286.

28. Savva SC, Lamnisos D, Kafatos AG. Predicting cardiometabolic risk: waist-to-height ratio or BMI. A meta-analysis. Diabetes Metab Syndr Obes. 2013;6:403-419.

29. Correa MM, Thume E, De Oliveira ER, et al. Performance of the waistto-height ratio in identifying obesity and predicting non-communicable diseases in the elderly population: A systematic literature review. Arch Gerontol Geriatr. 2016;65:174-182.

30. Lo K, Wong M, Khalechelvam P, et al. Waist-to-height ratio, body mass index and waist circumference for screening paediatric cardio-metabolic risk factors: a meta-analysis. Obes Rev. 2016;17(12):1258-1275.

31. McCarthy HD, Ashwell M. A study of central fatness using waist-to-height ratios in UK children and adolescents over two decades supports the simple message-'keep your waist circumference to less than half your height'. Int J Obes (Lond). 2006;30(6):988-992.

32. Kazlauskaite R, Avery-Mamer EF, Li H, et al. Race/ethnic comparisons of waist-to-height ratio for cardiometabolic screening: The study of women's health across the nation. Am J Hum Biol. 2017;29(1):22909.

33. Taylor RW, Williams SM, Grant AM, et al. Predictive ability of waistto-height in relation to adiposity in children is not improved with age and sex-specific values. Obesity (Silver Spring). 2010;19(5):1062-1068.

34. Yoo EG. Waist-to-height ratio as a screening tool for obesity and cardiometabolic risk. Korean J Pediatr. 2016;59(11):425-431.

35. Ashwell M, Gibson S. A proposal for a primary screening tool: 'Keep your waist circumference to less than half your height'. BMC Med. 2014; $12: 207$

36. Rodriguez-Perez MC, Orozco-Beltran D, Gil-Guillen V, et al. Clinical applicability and cost-effectiveness of DIABSCORE in screening for type 2 diabetes in primary care. Diabetes Res Clin Pract. 2017;130:1523

37. Gray L. Central obesity and waist-to-height ratio as proxy for routine health risk assessment. In response to Waist measurement, not BMI, is stronger predictor of death risk, study finds. BMJ. 2017;357:j2033.

38. Lim LL, Seubsman SA, Sleigh A, et al. Validity of self-reported abdominal obesity in Thai adults: a comparison of waist circumference, waist-to-hip ratio and waist-to-stature ratio. Nutr Metab Cardiovasc Dis. 2012;22(1):42-49.

39. Thaikruea L, Yavichai S. Proposed Waist Circumference Measurement for Waist-to-Height Ratio as a Cardiovascular Disease Risk Indicator: Self-Assessment Feasibility. Jacobs Journal of Obesity. 2015;1(2):1-7.

40. Stockport Council: Don't string yourself along: measure your waist to height ratio.

41. SHINE Health Academy Sheffield: 'Don't waist time' poster. 